\title{
Laparoskopik ve Robotik Pyeloplasti: Teknik İpuçları
}

\author{
Ali Tekin ${ }^{1}$, Burak Turna ${ }^{2}$
}

${ }^{1}$ Ege Üniversitesi, Tıp Fakültesi, Çocuk Ürolojisi Bilim Dalı, İzmir

Ege Üniversitesi, Tıp Fakültesi, Üroloji Anabilim Dalı, İzmir

\begin{abstract}
Giriş
'lk kez 1990'lı yılların başlarında tarif edilen laparoskopik pyeloplasti günümüzde üreteropelvik bileşke obstrüksiyonunun (ÜPBO) tedavisinde en çok tercih edilen tedavi yaklaşımı olarak ön plana çıkmıştır (1). Her ne kadar endopyelotomi gibi endoskopik seçenekler daha az invaziv olsa da; bu yöntemlerin uzun dönemde başarısının düşüklüğü ÜPBO tedavisinde minimal invaziv pyeloplasti seçeneğini ön plana çıartmaktadır (2). Literatürde farklı pyeloplasti teknikleri tanımlanmıştır. Biz, kliniğimizde, hem primer hem de sekonder pyeloplasti operasyonlarında yüksek başarı oranı nedeniyle siklıkla Anderson-Hynes dismembered pyeloplasti tekniğini tercih etmekteyiz. Ancak çaprazlayan damar olmayan ve hidronefroz derecesi düşük olgularda Fengerplasti tekniği bir seçenek olabilir. Bununla birlikte, yüksek girişli bir üreterde ise $\mathrm{Y}-\mathrm{V}$ plasti tercih edilebilir. Biz bu derlemede, laparoskopik ve robotik pyeloplasti olgularından edindiğimiz tecrübeye dayanarak meslektaşlarımıza bu operasyonlara yönelik bazı teknik ipuçlarını vermeyi amaçladık.
\end{abstract}

\section{Endikasyonlar}

Kronik veya bol sıvı alımı sonrası epizodik yan ağrısı olması, enfeksiyon, böbrek fonksiyonunda kayıp veya böbrek taşı oluşması ÜPBO olan olgularda erişkinlerde pyeloplasti endikasyonlarını oluşturur. Biz genellikle herhangi bir nedenle yapılan ultrasonografide unilateral hidronefroz saptanan genç erişkin olguların ileri değerlendirilmesi neticesinde tanıyı koymaktayız. Bu olgularda, eşlik eden böbrek taşının olup olmadığının preoperatif dönemde belirlenmesi önemlidir. Ayrıca diüretikli böbrek sintigrafisinde obstrüksiyon varlığının ortaya konulması ve karşılaştırmalı böbrek fonksiyonlarının hesaplanması gereklidir. Seçilmiş olgularda retrograd pyelografi yapılarak üreteropelvik bileşke (ÜPB) anatomisi ortaya konur. Üreteropelvik bileşkeye oturmuş taşlarda ise öncelikle taşın tedavisi, hasta taşsız kaldıktan sonra ÜPB'nin yeniden değerlendirilmesi tavsiye edilir. Endopyelotomi yapılmayacak olgularda preoperatif dönemde anjiyografik bilgisayarlı tomografinin istenmesine gerek yoktur. Ancak, laparoskopik veya robotik pyeloplasti sirasında çaprazlayan damar varlığının \%40-50 oranında saptanabileceğini göz önünde bulundurarak bu vasküler yapıları korumak önemlidir. Bununla birlikte, bizim deneyimimize göre çaprazlayan damarları her zaman transpoze etmek gerekmemektedir.

\section{Yaklaşım}

Yeterli deneyim ve ekipman olduğu takdirde minimal invaziv pyeloplasti için hem laparoskopik hem de robotik yöntem uygun yöntemlerdir. Her iki tekniğin de; başarı ve komplikasyon oranları birbirine yakındır (3). Her iki yöntem için de, hem retroperitoneal hem de transperitoneal yaklaşım tanımlanmıştır. Ancak, biz kendi merkezimizde, büyük çalışma alanı ve çaprazlayan damarların daha iyi değerlendirilmesi nedeniyle transperitoneal yaklaşımı tercih etmekteyiz. Son 2 yıldır merkezimizde, pyeloplasti ameliyatlarında, 3 boyutlu görüntü, 540 derece hareket kabiliyeti, 7 derecelik hareket serbestliği, daha iyi ergonomi ve tremorun ortadan kalması nedeniyle robotik yöntemi tercih ediyoruz. Ancak robotun maliyetinin yüksek oluşunun ,bu teknolojinin yaygin olarak kullanılmasının engellemesini de önemsiyoruz.

\section{Enstrümantasyon}

Laparoskopik pyeloplasti için tipik olarak 3 port yaklaşı$\mathrm{ml}$, robotik pyeloplasti için ise tipik olarak 4 port yaklaşımı kullanmaktayız. Laparoskopik pyeloplasti prosedüründe, küçük barsak grasper'1, laparoskopik makas ve laparoskopik portegüler kullanıyoruz. Robotik pyeloplasti operasyonlarını ise 3 robotik port ve 1 adet laparoskopik asistan portu yard1$\mathrm{m}$ ile gerçekleştiriyoruz. Robotik Prograsp forceps, robotik makas ve robotik portegü tercih ettiğimiz enstrümanlardır. Her iki teknikte de; laparoskopik aspiratör kullanıyoruz. Anastomoz için ise tercihen $5 / 8$ iğneli $20 \mathrm{~cm}^{\prime}$ lik 2 adet $4 / 0$ Vicryl kullanıyoruz. Yirmi sekiz $\mathrm{cm}$ uzunluğundaki $6 \mathrm{Fr}$ double J stenti antegrad yolla yerleştirmeyi tercih ediyoruz.

\section{Teknik}

Intratrakeal genel anesteziyi takiben, hasta patoloji olan taraf üstte olacak şekilde 60 derecelik modifiye flank pozisyonuna yatırılır. Kontrlateral kol karşıya ve önkol dirsekten 90 derece kırılacak şekilde, ipsilateral kol ve önkol karşıya bakacak şekilde yerleştirip her iki kol arasına yastık konularak kollar tespit edilir. Kotrlateral koltuk altına meme hizasından aksiller rulo yerleştirilir. Altta kalan bacak 45 derece, üstte kalan bacak 10 derece kadar bükülür. Bası oluşabilecek her nokta incelenip rulolar ve kompreslerle desteklenir. Pozisyon verildikten sonra hasta masaya teypler ile tespit edilir ve ksifoid çıkıntıdan pubik simfizise kadar \%10'luk povidin iyodür solüsyonu ile boyanır. 
Sağ Laparoskopik Pyeloplasti

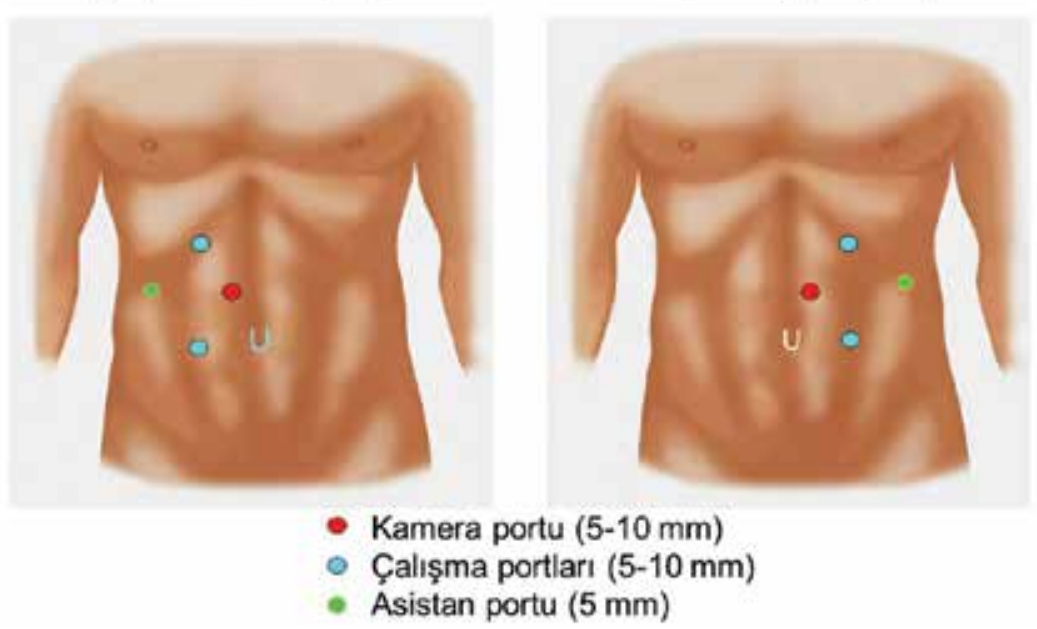

Şekil 1
Sağ Robotik Pyeloplasti

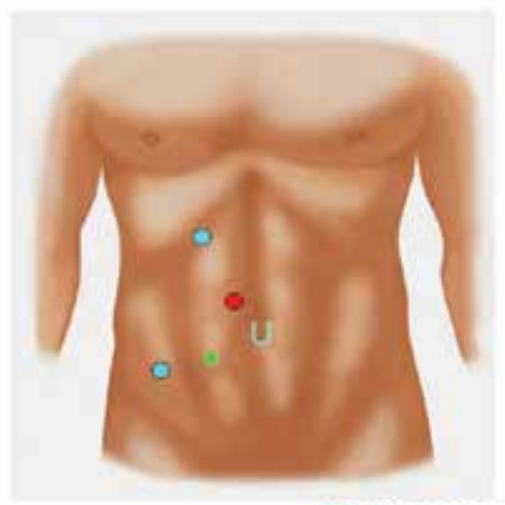

- Kamera portu $(12 \mathrm{~mm})$

- Robotik portlar $(8 \mathrm{~mm})$

- Asistan portu $(5 \mathrm{~mm})$
Sol Robotik Pyeloplasti

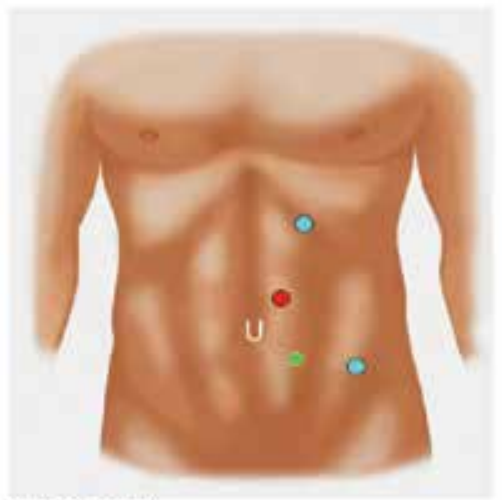

Şekil 2

Şekil 1 ve Şekil 2'de sırasıyla, laparoskopik ve robotik pyelopasti için kullandığımız port yerleşimleri görülmektedir.

Laparoskopik pyeloplasti için ilk giriş, Veres iğnesi ile, umblikusla spina iliaka anteior superior (SİAS) arasında oluşturulan hayali çizginin, rektus abdominis kasının lateral kenarı ile kesiştiği noktadan yapılır. Karbondioksit insuflasyonu sonrası, bu noktadan ilk port girilir (sağ laparoskopik pyeloplasti için sol el çalışma portu, sol laparoskopik pyeloplasti için sağ el çalışma portu). Ardından, kostal marjinin yaklaşık 2 parmak altından, ilk portun kraniyelinden, lateral rektus çizgisinden diğer el portu girilir. Kamera portu ise bu portun yaklaşık 4 parmak inferiorundan ve medialinden girilerek triangulasyon oluşturulur. Bazen, lateralden üreteri asmak için bir asistan portu daha eklenir.

Robotik pyeloplasti için ise ilk giriş umblikusun 2 parmak superiorundan ve lateralinden sağlanır. Karbondioksit insuflasyonu sonrasında ise bu nokta $12 \mathrm{~mm}$ 'lik robotik kamera portu olarak kullanılır. Ardından sağ pyeloplasti için sağ robotik port, sol pyeloplasti için sol robotik port, kostal marjinin 2 parmak altından, rektus kasının lateral kenarından yerleştirilir. Diğer robotik port ise SİAS'ın yaklaşık 4 parmak superior ve medialinden yerleştirilir. Asistan portu ise bu portun medialinden yerleştirilir. Portlar yerleştirildikten sonra robot hastanın sırtından yanaştırılır (Şekil 3).

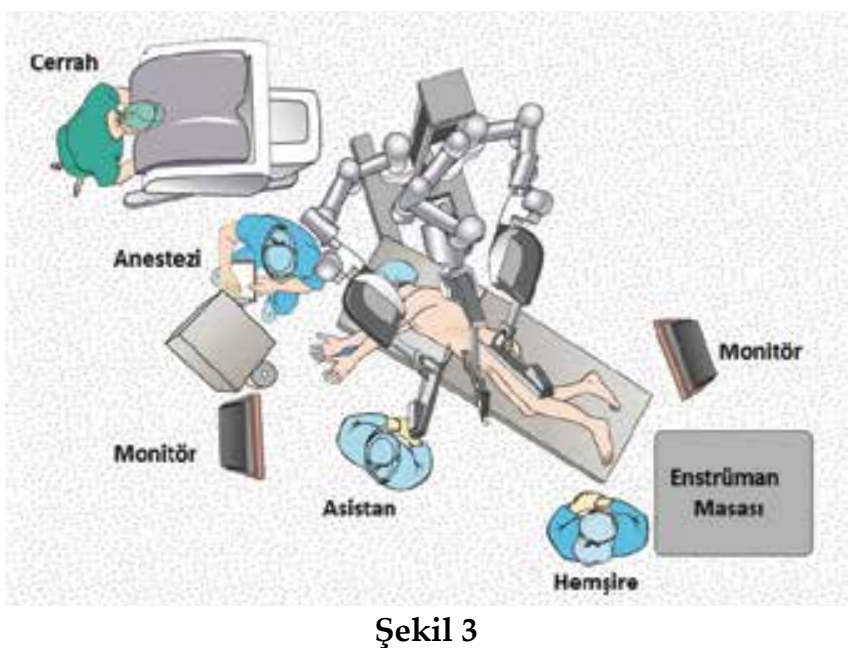




\section{LAPAROSKOPIK VE ROBOTIK PYELOPLASTI: TEKNIK IPUÇLARI}

Hasta tarafına göre, öncelikle inen ya da çıkan kolon mediale devrilebileceği gibi özellikle çocuk ve zayıf hastalarda transmezenterik diseksiyon tercih edilir. Sağ tarafta duodenum koherize edilir. Ardından, sağda inferior vena cavanın lateralinden, solda ise aortanın lateralinden Gerota fasyası açılır. Psoas kası ortaya konduktan sonra non dominant el ile gerota fasyası yukarı kaldırılarak, üreter ve/veya gonadal ven ortaya konur (Şekil 4). Bu aşamada gonadal ven medialize edilirken, üreter lateralize edilir. Non-dominant el üreterin altından geçirilerek dominant elle üreter kraniale doğru diseke edilir. Bu diseksiyonu kolaylaştırmak için laparoskopik pyeloplastide, Gerota fasyası Weck kliplerle, robotik pyeloplastide ise 0 Vicryl ile karın yan duvarına lateral retraksiyon için asılır (Şekil 5).

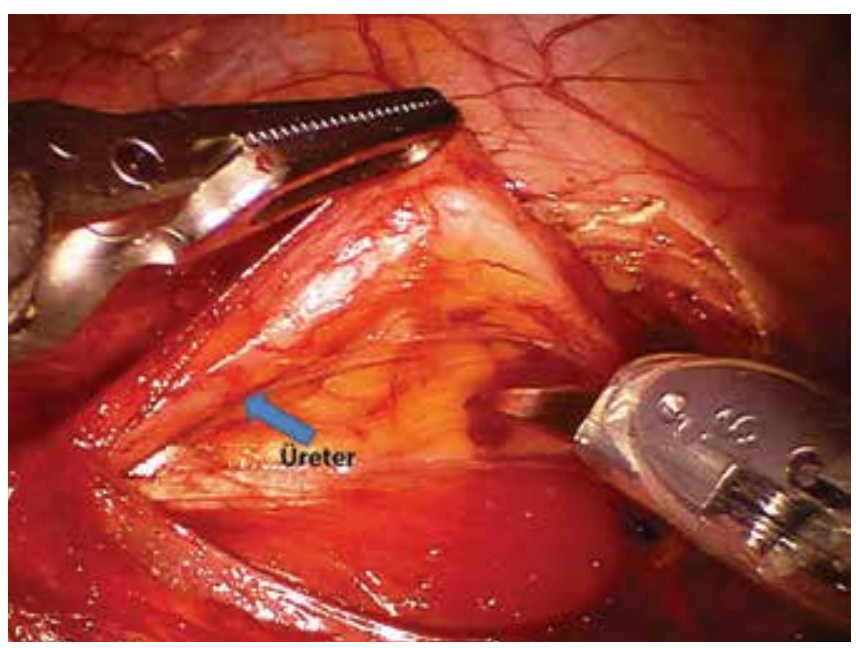

Şekil 4

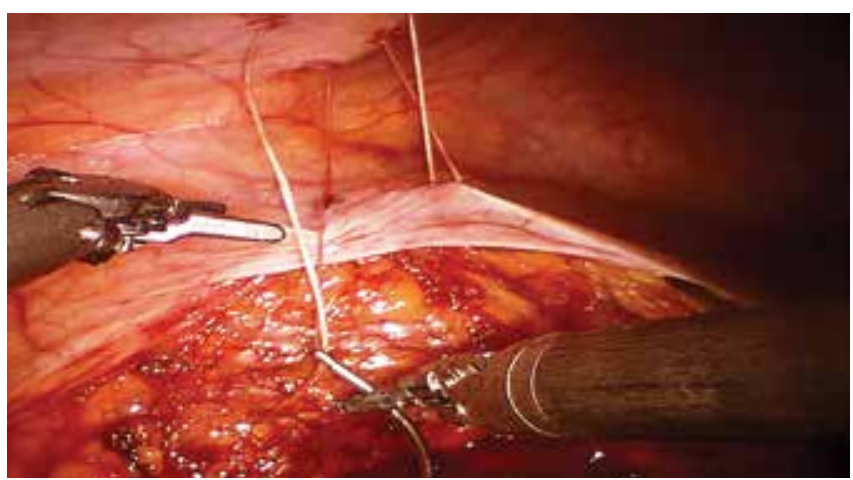

Şekil 5

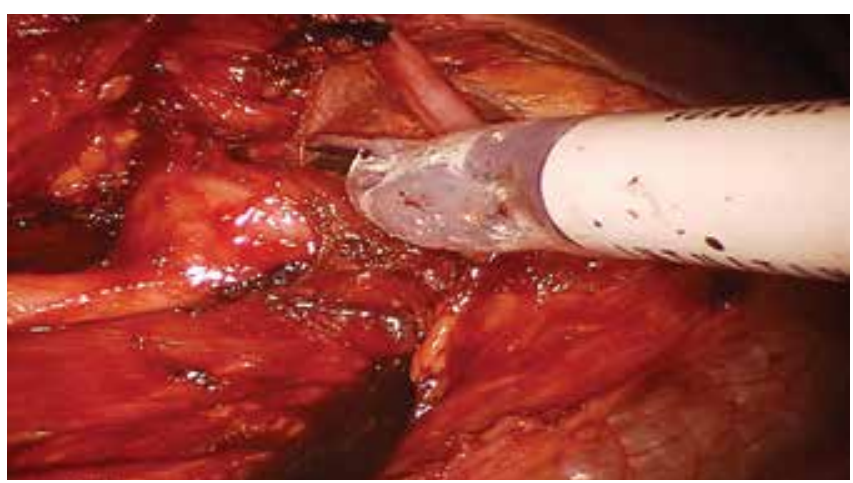

Şekil 6
Üreteropelvik bileşkeye yaklaşılırken olası çaprazlayan damar varlığına karşı diseksiyon dikkatli yapılmalıdır (Şekil 6). Kliniğimizde, bu diseksiyon için laparoskopik pyeloplastide çoğunlukla laparoskopik J-hook'u tercih ederken robotik cerrahide robotik makası kullanmaktayız. Çaprazlayan damar varlığında pelvis ve çaprazlayan damar birbirinden ayrılacak şekilde diseksiyon yapılmalı ve pelvis geniş olarak ortaya konulmalıdır. Bu aşamadan sonra ameliyat tekniğine karar verilir. Bu karardan sonra, ÜPB hizasından üreter, renal pelvisten ayrılır (dismembered). Bu aşamada üreter ile renal pelvis arasında, daha sonraki spatülasyonu kolaylaştıracak bir doku bırakmak yararlı olacaktır. Proksimal üreter beslenmesi medialden olduğu için üreter spatülasyonu lateralden yapılır (Şekil 7). Spatülasyon yapılırken cömert davranılmalıdır. $\mathrm{Bu}$ aşamada renal pelvis redüksiyonunun yapılıp yapılamayacağı renal pelvis hacmi ile ilişkili olarak belirlenir. Bizim düşüncemize göre renal pelvis redüksiyonu her zaman gerekmemektedir.

Anastomoz 4/0 Vicryl ile kontinü dikişlerle yapılır. Pelvisin en alt noktası ve üreter spatülasyonunun bitiş noktasından anastomoza başlanır (Şekil 8). Düğüm dışarıda kala-

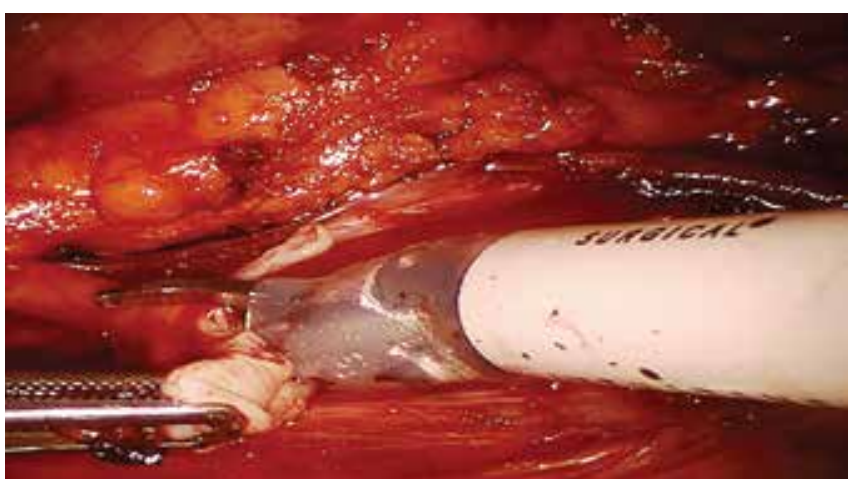

Şekil 7

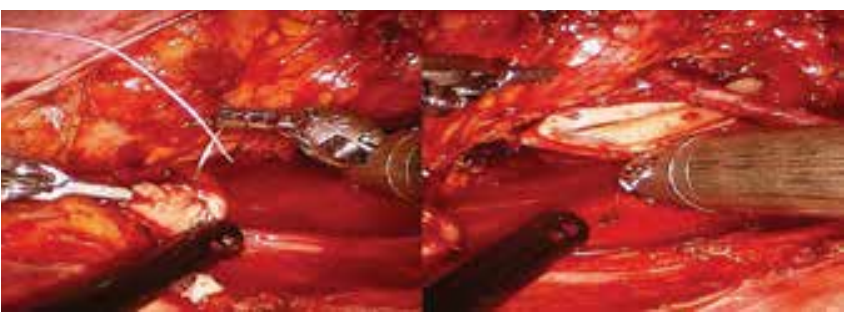

Şekil 8

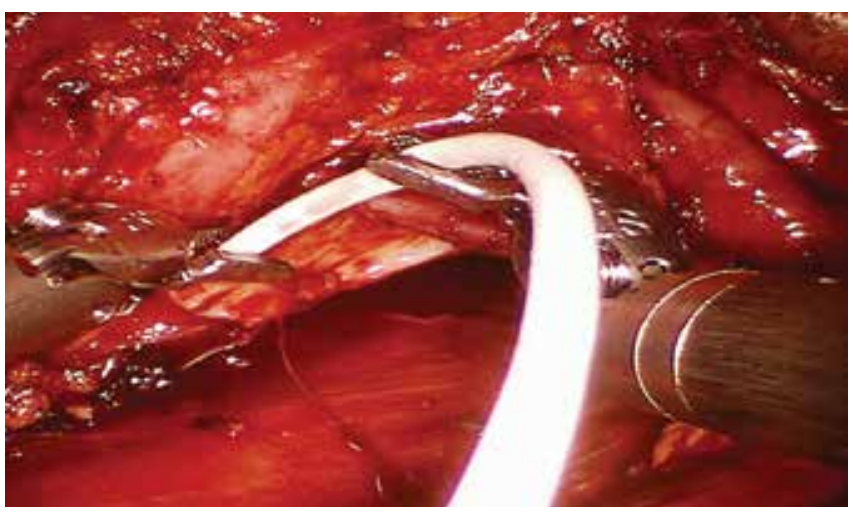

Şekil 9 


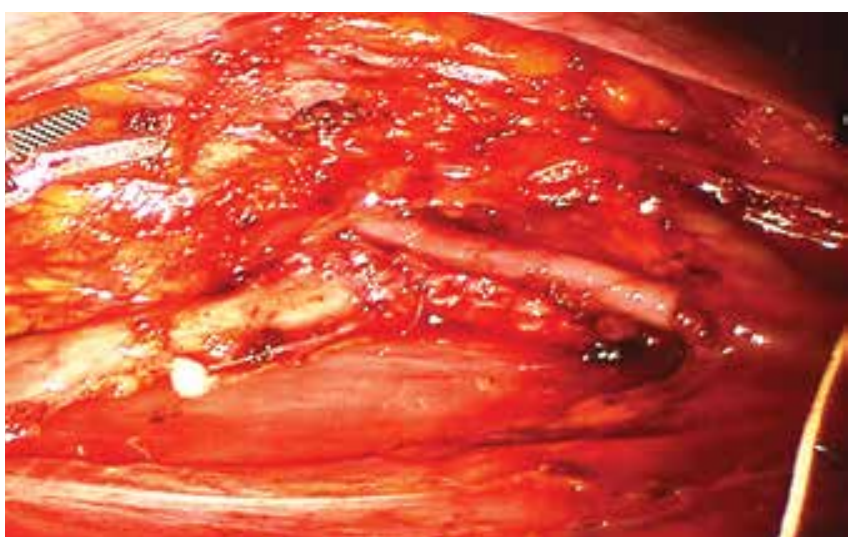

Şekil 10

cak şekilde ilk dikiş bağlanır. Anterior yüz kontinü 4 kadar dikişle anastomoz edilir. Laparoskopik pyeloplastide, iğne bu aşamada forehand olarak tutulur. Anterior yüzün anastomozu tamamlandiktan sonra double J stent antegrad olarak yerleştirilir (Şekil 9). Ardından anterior anastomoz sütürünün ucundan, laparoskopik veya robotik asistan kolla tutularak posterior yüzün gösterilmesi sağlanır. Spatülasyonun bittiği noktadan, ilk düğümün hemen yanından anastomoza başlanır. Laparoskopik pyeloplastide, bu aşamada sütürün iğnesi portegüyle backhand olarak tutulmalıdır. Posterior yüzün anastomozu bittikten sonra her iki iplik birbirine bağlanır. Anastomozu yaparken, darlığa sebep olmamak için, sütürlerin üretral mukozadan ince, pelvisten ise kalın geçmeye özen gösterilmelidir. Özellikle transperitoneal yöntemde, anastomoz tamamlandiktan sonra anastomuzun su geçirmez olduğundan emin olmak gerekir (Şekil 10).

Anastomoz tamamlandiktan sonra renal pelvis redüksiyonu yapılabilir. Pelvis redüksiyonu yapılırken, tutmak için kraniyal uçta bir miktar doku bırakmak pelvisi damarlardan uzak tutar ve pelvik anastomozu kolaylaştırır. Pelvis $3 / 0$ vicryl ile kontinü anastomoz edilir. İlk dikişten sonra fazla doku eksize edilerek, pelvotomi ÜPB'e kadar kontinü olarak kapatilir.

Renal toplayıcı sistemde bir veya birden fazla taş varlığında geniş bir pelvotomi yapılır ve ardından pelvis, laparoskopik barsak tutucu veya robotik ProGrasp ile tutularak taş ortaya konmaya ve çıkarılmaya çalışılır. Eğer başarısız olunursa irrigasyonu tutacak bir hacme kavuşması için pelvotomi açıklığı küçültülür, pelvis irrige edilir ve endoskopik olarak pyelolitotomi denenir. Bu amaçla herhangi bir porttan fleksible sistoskop girilebilir. Taşı çıkarmak için basket kateter kullanılabilir. Litotomi sonrası anastomoz daha önce tarif edildiği şekilde tamamlanır.

Özellikle geniş port yerlerindeki fasya iyi kapatılmadığ takdirde insizyonel herni gelişebileceği unutulmamalıdır. $\mathrm{Bu}$ nedenle kliniğimizde laparoskopik veya robotik ameliyatların sonunda $5 \mathrm{~mm}$ 'den büyük portların fasyasına kamera rehberliğinde Carter-Thomason ile 0 vicryller yerleştirilmektedir. Kamera portunun yerinden $12 \mathrm{Fr}$ çaplı dren pararenal alana bırakılır. Ardından portlar çıkarılarak gaz desüfle edilir ve fasyal dikişler bağlanır. Ciltaltı $2 / 0$ Vicryl ile tek tek kapatılır. Cilt subkutiküler olarak 3/0 Vicryl ile kontinü kapatilir.

Daha önce pyeoplasti ya da ÜPBO'a yönelik endoskopik girişim geçirmiş olgularda pyeloplasti oldukça zorludur. Bu olgularda laparoskopik teknik kullanılabilir ancak tecrübelerimize göre robotik enstrümantasyon önemli bir avantaj sağlamaktadır. Girişim planlanmadan önce böbrek fonsiyonu ve striktürün uzunluğu görüntüleme yöntemleri ile belirlenmeli ve spiral flep, ileal interpozisyon veya ototransplantasyon gerekliliği ortaya konulmalıdır.

Pyeloplasti yapılacaksa, üreter ve pelvis arasındaki mesafenin çok açılmaması için, masaya fleksiyon verilmemelidir. Striktür alanının iyi gözlenebilmesi için proksimal üreter, ÜPB ve renal pelvisin etrafındaki skar dokusu tam olarak diseke edilmelidir. Bu diseksiyon düzgün yapılmazsa rezeksiyon yanlış yerden yapılabilir ve elde anastomoza izin vermeyecek kadar kısa bir üreter kalabilir. İyi bir anastomoz için yeterli üreter uzunluğuna ihtiyaç vardır, bu nedenle yalnızca striktür rezeke edilmeli, normal üreter dokusu ve normal pelvis dokusu harcanmamalıdır. Üreter lateralden, pelvis medialden spatüle edilerek geniş bir anastomoz açıklığı oluşturulur. Peripelvik ve periüreteral dokuların 2-3 adet 3/0 sütürle tutturularak gerginliğin azaltılması, daha sağlıklı anastomoza izin verecektir. Anastomoz daha önce tarif edildiği gibi kontinü olarak yapılabilir. Üreter ve pelvis gergin olarak bir araya geliyorsa anastomozu tek tek yapmak daha güvenli olacaktır.

\section{Postoperatif dönem}

Olguların genelinde postoperatif bakımı standarttır. Postoperatif 1. günde Foley sonda çekilir. Aynı günün akşaminda drenden gelen sıvının kreatinin seviyesi değerlendirilir. Kreatinin seviyesi serum ile aynı ise dren ertesi sabah çekilir ve olgu taburcu edilir. Dört hafta sonra double J stent çekilir ve bu aşamadan 1-2 ay sonra diüretikli renal sintigrafi yapilir.

\section{Sonuç}

Robotik ve laproskopik pyeloplasti, tecrübeli ellerde efektif ve güvenilir minimal invaziv tekniklerdir. Sütür atma becerisindeki mükemmellik ve özellikle sekonder olgulardaki teknik avantajlar, robotik pyeloplastiyi ön plana çıkarmaktadir.

\section{Kaynaklar}

1. Schuessler WW, Grune MT, Tecuanhuey LV, Preminger GM: Laparoscopic Dismembered Pyeloplasty. J Urol 1993, 150(6):1795-1799.

2. Van Cangh PJ, Wilmart JF, Opsomer RJ, Abi-Aad A, Wese FX, Lorge F: Long-Term Results and Late Recurrence After Endoureteropyelotomy: A Critical Analysis of Prognostic Factors. J Urol 1994, 151(4):934-937.

3. Ficarra V, Iannetti A, Vianello F, Mottrie A: Different Pyeloplasty Approaches, Similar Excellent Results. Eur Urol.http://dx.doi.org/10.1016/j.eururo.2013.06.053.

Yazışma Adresi:

Burak Turna

Ege Üniversitesi, Tıp Fakültesi, Üroloji Anabilim Dalı,

Bornova 35100, Izmir

Tel: +902323747174

e-mail: burakturna@gmail.com 